\title{
Resíduos Medievais em Raquel Naveira ${ }^{1}$
}

\author{
Mary Nascimento da Silva Leitão²
}

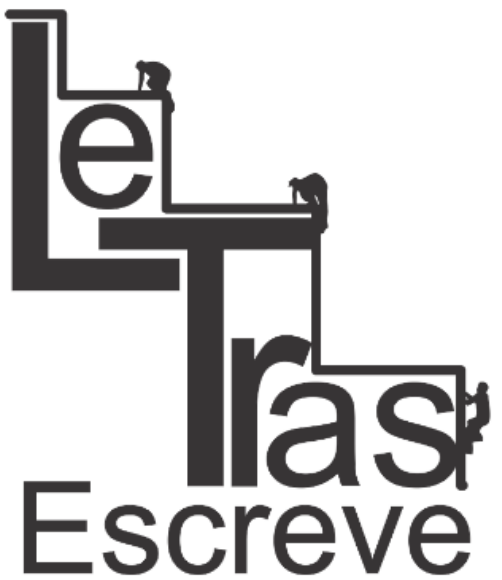

(ISSN 2238-8060)
Resumo: O poema "Burca", inserido em Portão de Ferro, da escritora sulmato-grossense Raquel Naveira, resgata a representação de uma mulher que negativamente venceu o tempo e persiste ainda na atualidade. Tratase da figura daquela que vive aprisionada dentro de uma veste que em culturas fora do Brasil ainda encontram sentido de existência. Referida representação surge no poema de Raquel Naveira também de forma metaforizada, fazendo-nos resgatar a própria história da mulher ao longo dos tempos, em especial na Idade Média, em que o ser feminino, segundo Le Goff \& Truong (2014, p. 52), subordinava-se ao homem tanto no âmbito espiritual quanto no corporal. Tais ideias, tão propagadas na época, são frutos de uma concepção cristã, difundida através dos textos bíblicos. $O$ estudo que possibilita identificar e compreender esses traços de mentalidade medieval presentes num texto atual diz respeito à residualidade (PONTES, 2015), teoria que sistematiza as noções de resíduo, cristalização, hibridismo cultural e mentalidade, mostrando a importância de elementos antigos que ultrapassam as barreiras do tempo e, vivos, influenciam na formação de "novas" culturas e de "novos" modos de pensar o mundo.

Palavras-chave: Burca; Mulher; Residualidade; Medievalidade.

Abstract: The poem "Burca", set in the Portão de Ferro, written by Raquel Naveira, born in Mato Grosso do Sul, Brazil, rescues the representation of a woman that negatively won the time and still persists today. This is the figure that living imprisoned in a robe that, in cultures outside of Brazil, still find sense of existence. Such representation appears in Raquel Naveira poem in a metaphorized way, making us rescue the history of women over time, especially in the Middle Ages, in which being female, according to Le Goff \& Truong (2014, p. 52 ), was subordinated to man both in the spiritual realm as in the corporal. Such ideas, as propagated at the time, are the fruit of a Christian view, propagated by the biblical texts. The study that helps identify and understand these traces of medieval mentality present in the current text with regard to residuality (BRIDGES, 2015), a theory that explores the residue notions, crystallization, cultural hybridity and mentality, showing the importance of old elements that go beyond barriers of time and living, influence the formation of "new" cultures and "new" ways of thinking about the world.

Keywords: Burca; Woman; Residuality; Medievalidade.

1 Este trabalho é a ampliação de um trecho do trabalho intitulado "RESÍDUOS HISTÓRICOS DO IMAGINÁRIO FEMININO EM PORTÃO DE FERRO, DE RAQUEL NAVEIRA" apresentado no Simpósio Nacional do GEPELIP: Interculturalidade nas Literaturas de Língua Portuguesa, na Universidade Federal do Amazonas (MANAUS), em 2014.

2 Doutoranda em Letras pela Universidade Federal do Ceará. Orientada pela Profa. Dra. Elizabeth Dias Martins. E-mail: maryepoesia@gmail.com.

https://periodicos.unifap.br/index.php/letras

Macapá, v. 6, n. I, Io semestre, 2016. 


\section{Introdução}

De acordo com Roberto Pontes (1999), "escrever poesia é exatamente o maior compromisso que pode um homem firmar consigo mesmo" (PONTES, 1999, p. 24). De fato, quando nosso olhar se volta para a obra de Raquel Naveira, o pensamento de Pontes (1999) não apenas confirma-se como também se amplia. Ao estudarmos a obra dessa autora, observamos a presença de diferentes temáticas como, por exemplo, as memórias portuguesas, os costumes mato-grossenses, a afetividade, a filosofia, o drama e a feminilidade. Trata-se de conteúdos que vão além de uma simples exposição sentimentalista, alcançando certo grau de comprometimento com suas raízes locais, com sua herança lusitana e com as mulheres de todas as épocas.

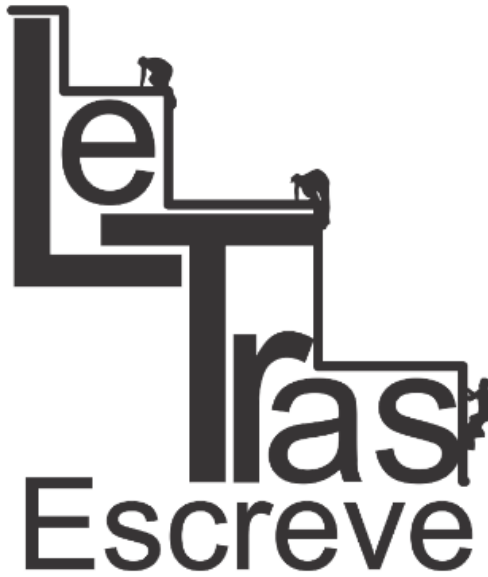

(ISSN 2238-8060)

Quando nos referimos à observação de comprometimento com as mulheres de todas as épocas na obra de Raquel Naveira, reportamo-nos à sutil defesa da classe feminina perceptível nos poemas que envolvem essa temática. A autora representa perfis tanto individuais quanto coletivos, mas ambos representativos da força do sexo que durante séculos foi considerado frágil. E é por isso que Raquel, através de seus textos e, mais especificamente, de sua poesia, firma um compromisso consigo, com a sociedade e com a história das mulheres.

Apesar de o imaginário feminino estar significativamente presente ao longo de toda a obra da poeta em estudo, decidimos escolher apenas um poema, pois julgamos ser a escolha suficientemente consistente para a construção desse trabalho. Acreditamos ser "a burca" um texto-modelo, que apresenta a imagem tantas vezes resgatada ao longo da produção literária de Naveira. O poema está inserido em Portão de Ferro (2007), no qual encontramos um resgate de memórias vivenciadas ao longo da trajetória da autora em sua cidade natal. Com 85 poemas, o livro foi construído a partir de histórias místicas e míticas, e o seu nome faz 
referência a um lugar na cidade de Campo Grande, cenário ideal para as idealizações de uma menina.

Portão de Ferro pode ser organizado seguindo três direções: a "memorialística", a "lírico-amorosa" e a "geral". A primeira envolve elementos da cultura mato-grossense, seja referente ao meio, economia ou costumes. A segunda articula-se em torno da afetividade, do drama e da feminilidade. E a terceira une caracteres filosóficos, delírios, relações com o mundo. Assim, nosso interesse recai sobre as representações do feminino, as quais serão apreciadas a partir da Teoria da Residualidade.

\section{Teoria da Residualidade}

Todos somos frutos de uma coletividade. A influência da família e da sociedade, de modo geral, contribui para a nossa gradativa formação como seres humanos. A esse processo damos o nome de endoculturação, que é a constante inserção de elementos das diversas culturas em nosso modo de ser, pensar e agir, com os quais temos contato ao longo da vida. Portanto, somos seres híbridos, resultantes da mistura de diferentes culturas, advindas de espaços e tempos também diversos. É comum identificarmos heranças dos nossos pais e avós tanto em aspectos físicos quanto em psicológicos. Isso porque, por mais que a modernidade nos surpreenda a cada dia com novas formas de olhar o mundo, carregamos marcas do passado difíceis de serem dissolvidas. Reportamo-nos a outros modos de enxergar o mundo, a outras mentalidades que, sendo de outras épocas, deixam resíduos fincados nas criaturas que constroem as sociedades de cada tempo, de cada cultura. Referidos resíduos são dotados de grande força, pois se cristalizaram, vencendo as barreiras dos tempos e das bruscas mudanças, e ainda têm significado na sociedade atual.

Esse processo natural que acabamos de descrever não parece novidade. De fato não é. Contudo, os conceitos acima 


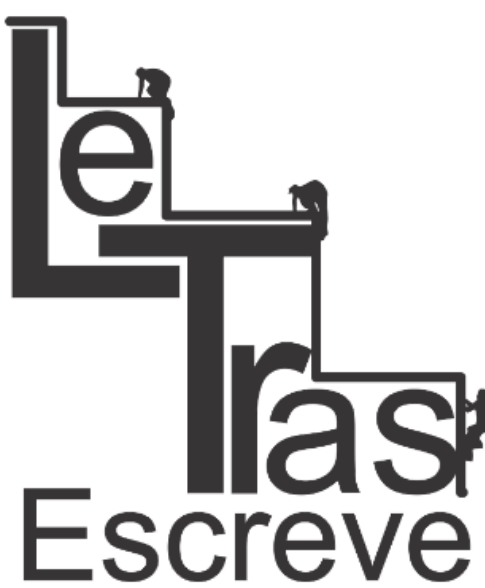

(ISSN 2238-8060) resgatados vêm sendo aprofundados e sistematizados por Roberto Pontes e um grupo de pesquisadores desde $1999^{3}$. Esses estudos têm os textos literários como base, já que muitos autores convencionados a fazerem parte de uma única estética, têm obras notavelmente híbridas, sendo essa classificação apenas uma necessidade didática. Desse modo, a literatura nos dá material suficiente para investigarmos o encontro de influências de diversas naturezas, principalmente histórico-culturais.

É preciso deixar claro que a Residualidade acontece no plano da mentalidade. Interessa à teoria, portanto, os modos de pensar, agir e se comportar de outras épocas constantemente encontradas em obras contemporâneas. Trata-se de um estudo interdisciplinar, o qual interliga-se às áreas lindeiras da literatura: sociologia, história, psicologia, antropologia, dentre outras. No caso de nossa pesquisa, realizamos uma análise histórico-literária, analisando o poema "A burca", inserido em Portão de Ferro, cuja imagem feminina representada é uma espécie de modelo retratado inúmeras vezes ao longo da produção naveiriana.

\section{Uma mulher por trás da burca}

Quando refletimos acerca da concepção de "feminino", não há como não pensar na noção de "masculino". Uma depende da outra. Desde a Idade Média, quando o Cristianismo encontrou seu ápice e a história da criação do mundo, baseada na Bíblia, esteve em evidência, a mulher era vista como uma peça necessária complementar ao sexo masculino. A imagem da boa mulher era constantemente propagada na época, já que o próprio Livro Sagrado apresentava os modos comportamentais adequados a ela:

Comportamento das mulheres - Quanto às mulheres, que elas tenham roupas decentes e se enfeitem com pudor e modéstia. Não usem tranças, nem objetos de ouro, pérolas, ou vestuário

3

https://periodicos.unifap.br/index.php/letras Macapá, v. 6, n. I, Io semestre, 2016. 


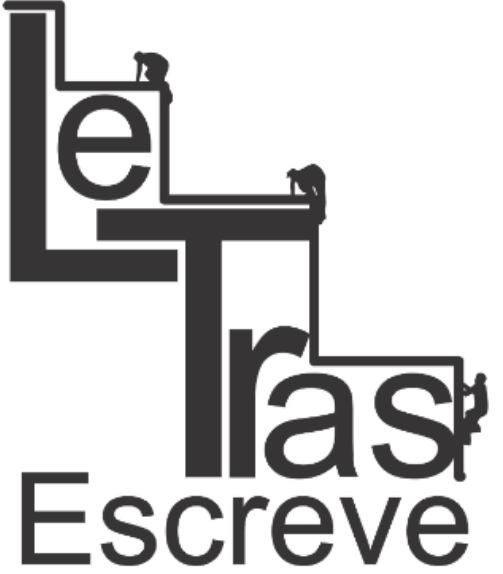

(ISSN 2238-8060) suntuoso, pelo contrário, enfeitem-se com boas obras, como convém a mulheres ser piedosas. Durante a instrução a mulher deve ficar em silêncio, com toda a submissão. Eu não permito que a mulher ensine ou domine o homem. Portanto, que ela conserve o silêncio. Porque primeiro foi formado Adão, depois Eva. E não foi Adão que foi seduzido, mas a mulher que, seduzida, pecou. Entretanto, ela será salva pela sua maternidade, desde que permaneça com modéstia na fé, no amor e na santidade (1Tm 2, 9-15).

Nota-se uma preocupação com o modo de vestir e de agir do sexo feminino. Provavelmente porque a imagem da mulher sempre foi símbolo de sedução, de perigo. Eva durante muito tempo foi referência nos sermões cristãos, nos quais essa representação era usada para lembrar que a mulher carrega consigo o peso do pecado original. A libertação só viria com a maternidade, pois com a dor sofrida durante o parto ela estaria pagando por todos os erros, inclusive aquele com o qual já nascera.

Toda essa inquietação gerada pelo sexo feminino é resgata no poema "a burca", de "Raquel Naveira", cujo tema parte da própria vestimenta, motivo de tantas discussões ao longo da História das Mulheres: 


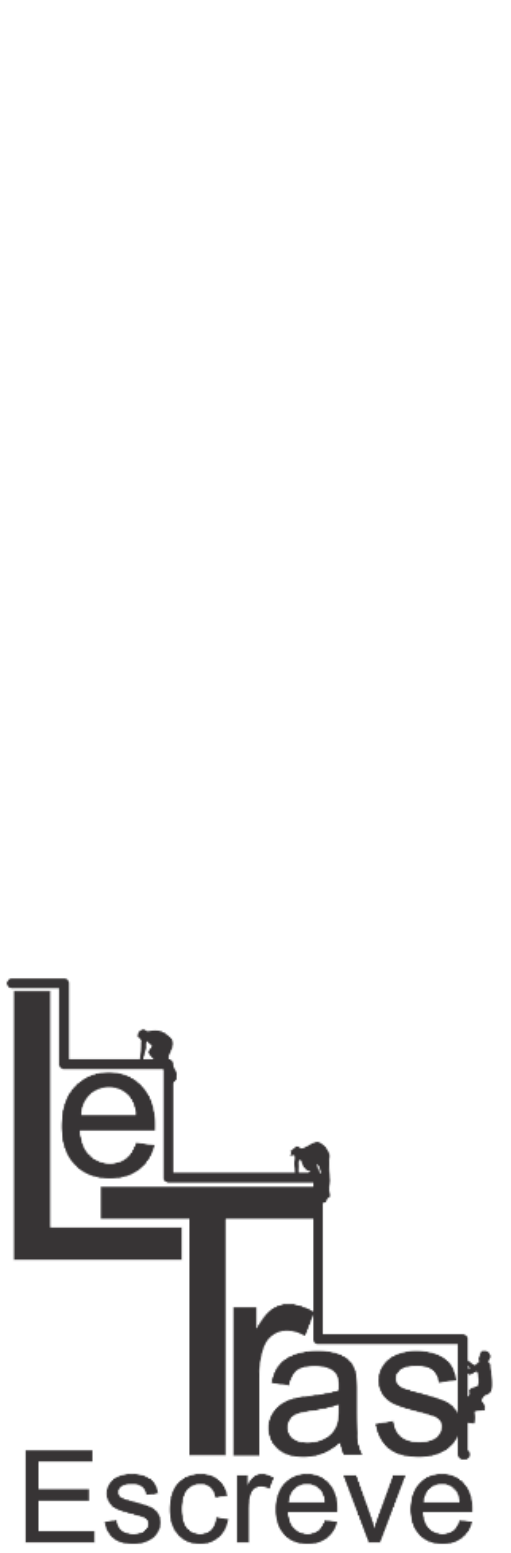

(ISSN 2238-8060)
Em suas mãos,

Em sua nuca,

Escorre larva quente;

Gota de fogo é o seu coração.

A mulher por dentro da burca

Tem algo de verme,

De serpente,

De pássaro,

É feita de neblina

A sua face triste.

Por dentro da burca

O medo sufoca,

A mulher segue a procissão

Com passos lentos,

Não permaneceria imóvel

Assistindo a procissão passar.

Por dentro da burca

A opressão enforca,

A mulher,

De costas viradas ao sol,

Enxerga sua sombra.

Por dentro da burca

A louca caminha pela praia,

A maré alta apagará suas pegadas.

A burca azulada como o céu

Torna a mulher

Invisível.

(NAVEIRA, 2006, p.17-18)

A burca é uma veste feminina que cobre todo o corpo e o rosto. Contudo, na parte dos olhos, o tecido é bem mais fino, sendo um espécie de tela que permite uma limitada visão do mundo. A mulher vê, mas não pode ser vista. E todos os desejos suscitados nela a partir do olhar devem ser contidos. Referida vestimenta é usada por mulheres do Afeganistão ou Paquistão; é símbolo do Talibã.

Desde o início do poema notamos ser a burca um símbolo de aprisionamento da mulher, não só pela resignação de sua imagem, mas pelo silêncio e pela persistência dessa "tradição" na atualidade. Mesmo com o menosprezo da figura feminina, nota-se a constante busca, por ela mesma, de um novo caminho: "Busca a estrada/ A 


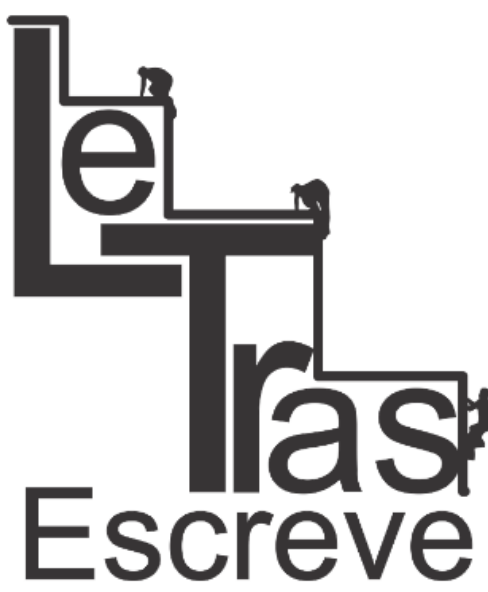

(ISSN 2238-8060)

repisada trilha de camelos/ Rumo ao Oásis". Oásis, não custa lembrar, é uma área isolada, localizada no deserto, com solo fértil e coberto por vegetação. Geralmente, há uma fonte de água por perto. Então, podemos inferir que mesmo em meio ao deserto, ao vazio, à invisibilidade, há uma esperança de vida, um anseio por mudança. No texto, observamos apenas o desejo por esse novo tempo, por esse novo espaço, mas não há realização, já que o caminho da mulher se "bifurca entre o amor e a morte".

A burca ocupa um espaço tão expressivo que chega a apagar a imagem da própria mulher. Mas, é preciso enfatizar que "há uma mulher por trás da burca". Por trás do silêncio há um vulcão, como bem destaca Raquel Naveira. Ela carrega a perspicácia de uma serpente e a sutileza de um pássaro. Ao invés de aceitar a condição de resignação, ela caminha, mesmo com o medo que a sufoca "por dentro da burca". A opressão a enforca. Até a sua sombra vive enclausurada, já que a vestimenta impede que ela veja a própria imagem.

No texto, a mulher também é caracterizada como "louca". Talvez isso aconteça pelo fato dela não parar de caminhar, mesmo aprisionada. A tentativa de seguir adiante, que acontece durante todo o texto, é substituída pela invisibilidade da imagem feminina. Por onde passa, ela não deixa marcas. "A maré apagará suas pegadas". E a burca "torna a mulher invisível", assim diz o poema.

É interessante o modo como a poeta faz esse jogo da imagem versus invisibilidade, da presença versus ausência. A imagem da burca torna a imagem da mulher inacessível. A figura feminina parece tornar-se invisível gradativamente durante o texto. Há uma espécie de refrão a cada início de estrofe que confirma o que foi dito. O poema começa com o verso "Há uma mulher por dentro da burca". Nas próximas quatro estrofes já notamos uma pequena modificação, pois iniciam-se com "a mulher por dentro da burca". Em seguida, mais uma redução acontece: "Por dentro da burca". E, na estrofe final, o início é apenas "a burca”. 


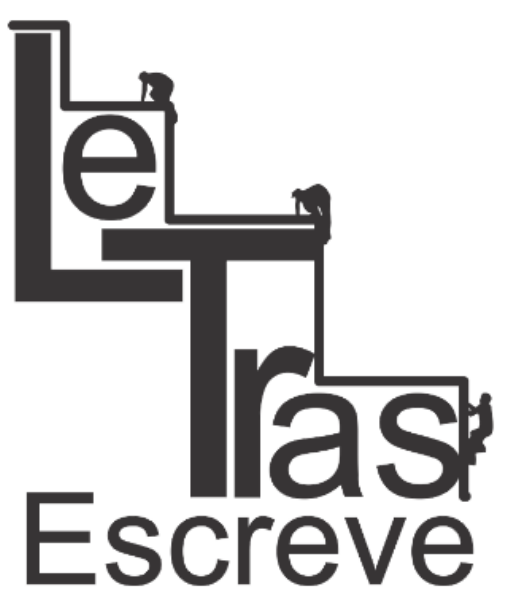

(ISSN 2238-8060)

As diversas antíteses, observadas ao longo do poema, também contribuem com esse jogo descrito acima. Os caminhos que se bifurcam entre amor e ódio, a caracterização da mulher como forte e marcante ao mesmo tempo que leve e invisível são exemplos desse duelo de contrários.

"A burca" apresenta resíduos que sempre estiveram presentes ao longo da História da Mulher. Essa vestimenta, sendo parte, ainda, da contemporaneidade, leva-nos a refletir sobre o aprisionamento tanto físico quanto psicológico. Trata-se de um elemento que pode ser analisado no seu sentido real e na sua face simbólica. Como símbolo, apresenta um arsenal de significações, a ser interpretado, em meio às diversas possibilidades, como um utensílio que tanto apaga quanto cala. O mundo mudou, mas esse resquício, por ser um resíduo, permanece vivo e repleto de sentido.

Acerca do silêncio e invisibilidade feminina, Perrot (2008), em Minha História das Mulheres, apresenta um comentário considerável:

Em muitas sociedades, a invisibilidade e o silêncio das mulheres fazem parte da ordem das coisas. É a garantia de uma cidade tranquila. Sua aparição em grupo causa medo. Entre os gregos é a stasis, a desordem. Sua fala em público é indecente. 'Que a mulher conserve o silêncio, diz o apóstolo Paulo. Porque primeiro foi formado Adão, depois Eva. E não foi Adão que foi seduzido, mas a mulher que, seduzida, caiu em transgressão. Elas devem pagar por sua falta num silêncio eterno" (PERROT, 2008, p.16-17).

Por não se ouvir a voz da mulher, pouco se falou dela na História. Vivia em silêncio e quase não aparecia em público. Ela mesma se resignava a isso. Portanto, não se pode contar a história de um ser invisível. As poucas que foram lembradas ficaram conhecidas como transgressoras, como é o caso de Cleópatra, que chegou a casar com o irmão para alcançar o poder. 
Mas, independentemente de serem invisíveis ou transgressoras, é importante lembrar que a maior parte da História fora relatada por homens. Só muito recentemente a mulher ganhou espaço suficiente para começar a contar aquilo que a História não registrou. Os estudos acerca do feminino datam de 1960 na GrãBretanha e Estados Unidos e de 1970 na França.

$\mathrm{Na}$ literatura não foi diferente. A escrita feminina não era valorizava porque pouco importava o pensamento de uma mulher. Ela mesma desvalorizava suas produções. De acordo com Michelle Perrot (2008), na maioria das vezes destruía seus textos, por medo de divulgá-los. E foi assim que se perpetuou uma imagem feminina, na literatura, sob o olhar masculino.

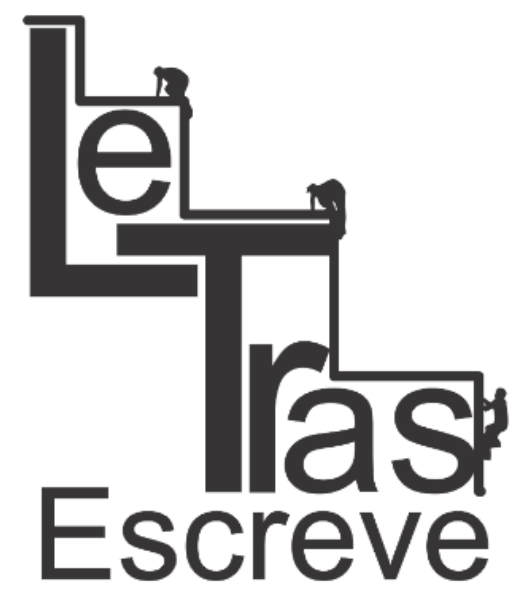

(ISSN 2238-8060)

A personagem feminina, construída e produzida no registro masculino, não coincide com a mulher. Não é sua réplica fiel, como muitas vezes crê o leitor ingênuo. É, antes, produto de um sonho alheio e aí ela circula, nesse espaço privilegiado que a ficção torna possível (BRANDÃO, 2004, p.11).

Em nossa pesquisa mostramos o contrário, pois se trata da imagem de uma mulher descrita pela própria mulher. Sem questionarmos se foi ou não intenção da autora, o poema aborda uma ampla reflexão que perpassa séculos. O corpo feminino ainda é causador de muitos problemas. A mulher parece ser vista mais como "serpente" do que como "pássaro".

Segundo Le Goff e Truong (2006), em Uma história do corpo na Idade Média, o ser feminino medieval enxergava no homem um "porto seguro", no qual teria forças e proteção. Em contrapartida, a mulher o servia de todas as maneiras. Portanto, a subordinação acontecia tanto no âmbito corporal quanto no espiritual.

Quando nos reportamos à Idade Média, queremos mostrar uma época em que era forte essa mentalidade de mulher submissa, calada e invisível, já que o cristianismo dominava o pensamento ocidental, com a solidez da Igreja Católica. Não nos referimos à origem de ideias ou pensamentos. Nunca teremos esse controle.

https://periodicos.unifap.br/index.php/letras Macapá, v. 6, n. I, Io semestre, 2016. 
Resgatamos, na verdade, traços de uma era que apesar de "distante", está presente em tantos elementos de nossa cultura, fazendo-nos mais uma vez ressaltar o fato de que nada é novo, tudo é residual.

\section{Referências bibliográficas}

BÍBLIA SAGRADA. Edição Pastoral. Paulus, São Paulo: 1990.

BRANCO, Lucia Castello \& BRANDÃO, Ruth Silviano. A mulher escrita. Rio de janeiro: Lamparina editora, 2004.

LE GOFF, Jacques. \& TRUONG, Nicolas. Uma história do corpo na Idade Média. [tradução: Marcos Flamínio Peres]. Rio de Janeiro: Civilização Brasileira, 2006

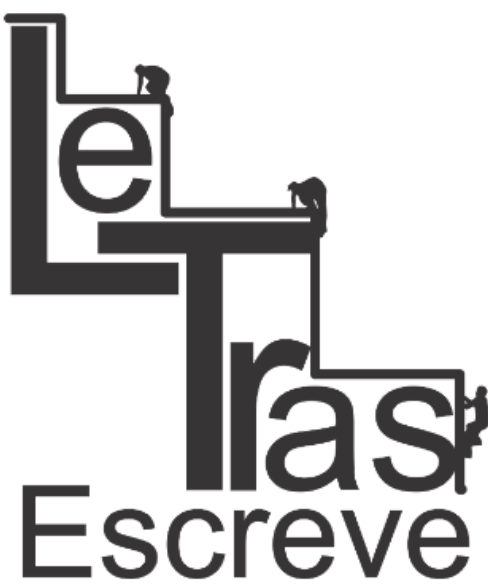

NAVEIRA, Raquel. Portão de Ferro. São Paulo. Escrituras: 2006.

PERROT, Michelle. Minha história das mulheres. [tradução Angela M. S. Corrêa]. - 1. ed., $1^{\text {a }}$ reimpressão - São Paulo: Contexto, 2008.

Recebido em 10/04/2016. Aprovado em 17/05/2016.

(ISSN 2238-8060) 